\title{
Strategies of Bringing Drug Product Marketing Applications to Meet Current Regulatory Standards
}

\author{
Yan Wu, ${ }^{1}$ Anita Freed, ${ }^{2}$ David Lavrich, ${ }^{1}$ Ramesh Raghavachari, ${ }^{3}$ Kim Huynh-Ba, ${ }^{4,7}$ \\ Ketan Shah, ${ }^{5}$ and Mark Alasandro ${ }^{6}$
}

Received 23 March 2015; accepted 8 May 2015; published online 30 May 2015

\begin{abstract}
In the past decade, many guidance documents have been issued through collaboration of global organizations and regulatory authorities. Most of these are applicable to new products, but there is a risk that currently marketed products will not meet the new compliance standards during audits and inspections while companies continue to make changes through the product life cycle for continuous improvement or market demands. This discussion presents different strategies to bringing drug product marketing applications to meet current and emerging standards. It also discusses stability and method designs to meet process validation and global development efforts.
\end{abstract}

At the 2014 American Association of Pharmaceutical Scientists (AAPS) annual meeting in San Diego, CA, Yan Wu (Merck) and Anita Freed (Pfizer) led a symposium entitled "Bringing Drug Product Marketing Applications to Current Regulatory Standards: Trials and Tribulations." This symposium was very timely as this topic is a growing industry concern, evidenced by over 300 attendees, and considering the new guidances (1-8) that have been established over the past decade. While most of these quality standards are applicable to new drug products, there is a risk that currently marketed products, known as legacy products, will not meet the new compliance standards during audits and inspections. Companies also need to continuously make process or method changes for in-line products as part of product life cycle management efforts or to meet different market needs. If legacy (or in-line) products undergo a change, the question is how much extra effort is needed to have these products meet current standards to support the associated submission. This symposium addressed these issues and offered modeling tools using existing data or other approaches and case studies to effectively manage post-approval changes. Presentations included the following:

- Modeling historical data to support process and method stability changes

- Food and Drug Administration (FDA) perspectives on application of International Conference on Harmonisation of Technical Requirements for Registration of Pharmaceuticals for Human Use (ICH) Q8 to legacy products

\footnotetext{
${ }^{1}$ Merck \& Co., Kenilworth, New Jersey, USA.

${ }^{2}$ Pfizer, Groton, Connecticut, USA.

${ }^{3}$ Food and Drug Administration, Silver Spring, Maryland, USA.

${ }^{4}$ Pharmalytik, Newark, Delaware, USA.

${ }^{5}$ Biogen, Cambridge, Massachusetts, USA.

${ }^{6}$ Allergan, Irvine, California, USA.

${ }^{7}$ To whom correspondence should be addressed. (e-mail: kim.huynhba@pharmalytik.com)
}

- Assessment of impact on stability with manufacturing, packaging, and/or method changes

- Applying Association of Southeast Asian Nations (ASEAN) stability requirements to legacy products and managing specifications across climatic zones

This paper provides an overview of the presentations and highlights strategies and points of consideration when bringing marketing applications of the legacy drug products to current and emerging standards.

\section{MODELING HISTORICAL DATA TO SUPPORT PROCESS AND METHOD STABILITY CHANGES, DAVID J LAVRICH, MERCK}

As formulations and processes are becoming more complicated and filing timelines are accelerating, the need for a risk-based approach to modeling of stability data is being realized, which is aligned with the quality by design (QbD) concept. In the past, a general approach to stability studies depended on end product testing, which was developed to analyze a number of target formulations, in target packaging, at various well-established stability stations (typically ICH conditions) and monitored against product stability specifications. If the product met its specifications after a certain amount of time on a specific station, the product was determined to be stable. In the current accelerated research and development paradigm, there is often less detailed knowledge available for the product and its stability at an early stage. The expectation is that more scientific details will be determined as the program matures through filing, typically along a QbD development strategy. Understanding the stability of a product poses unique challenges in fast-tracked program development timelines. Stability, by its nature, needs time to be understood. A failed stability study can set the program back significantly or lead to product recall. In addition, often times, specific product parameters and specifications may not be fully established at the time of 
stability study initiation. The use of risk-based modeling approaches to stability studies can help mitigate risks.

One technique using accelerated stability testing that has been discussed widely is the Accelerated Stability Assessment Program (ASAP) $(9,10)$. This strategy aims to predict long-term storage time based on the short-term performance of the product at high temperature and humidity, typically a few weeks above $50^{\circ} \mathrm{C}$ and at $75 \%$ relative humidity $(\mathrm{RH})$. Degradation kinetics at a few stations over a few weeks is extrapolated to lower temperatures and humidity for longer timeframes, on the order of months and years, using a modified Arrhenius approximation $(9,10)$. The advantages of this strategy are the short-term stability studies and fewer resources. Assuming a first order reaction, which is often the case for hydrolysis-based degradation, the degree of degradation is limited to 0.2 to $0.5 w / w \%$ so that over this range the reaction rates are likely to be linear. Such degradation can be achieved in a week or two at accelerated temperatures. This tool can provide a quick rank ordering of formulation and processes in 1-2 weeks. Disadvantages include reliance on a presumed kinetic model that limits degradation to less than a percent and extrapolation of three factors simultaneously: time, temperature, and humidity. These disadvantages are reduced when the case study involves "simple" kinetic pathways such as hydrolysis and the primary stability drivers are temperature and humidity. When the kinetic pathway is complex, nonlinear (first order and higher), involves physical changes such as phase transition and/or involves the impact of formulation or process factors (such as particle size, excipient levels, compression force, etc.), other models and experimental techniques are required. For example, in cases where elevated temperature and humidity cause the drug substance to change from crystalline to amorphous state or salt forms, an empiricalbased model may prove more advantageous (Fig. 1). In this example, the data is fit to a modified Arrhenius form and factorial form reduced to the statistically relevant terms. The modified Arrhenius form assumes a linear combination of temperature and humidity terms, while the factorial form adds an interaction term between temperature and humidity. The addition of these terms provides for a better fit overall and better agreement of data within the operating space of the model (at 25 and $30^{\circ} \mathrm{C}$ from 10 to $40 \% \mathrm{RH}$ ).

Typically, over the product development timespan, various experiments will be conducted at various stages by an assortment of researchers from different departments, each with their own specific scientific goals. The standard scientific approach has been one factor at a time (OFAT), where a factor of interest is changed to various settings while all other factors are held constant. One group might study the stability of a probe drug product (DP) that contains $0.5 \%$ excipient. Another group might examine the effect of the excipient on processability and decide upon a different amount. Still later, a group may conduct a single high temperature stability study of this formulation which may be manufactured at a different particle size. Oftentimes, this data is ignored by downstream research groups because it is viewed as originating from what appears to be a random collection of OFATs.

There is much to be learned from this data, however, with the application of exploratory data analysis (EDA) using statistical multivariate techniques such as ANOVA, PLS, PCA, etc. The impact of previously untested factors, interactions between factors, and a rough estimate of empirical models can often be determined. The results of this analysis can then be used to focus research efforts toward areas of interest and help with a designed statistical study using design of experiments (DOE) or other tools. Further, once the product is placed on formal stability study (FSS), the results can be compared back to the historical data sets. Figure 2 shows a composite of early probes using ASAP, late phase experimental stability studies, and the FSS data.

The advantage of applying these accelerating modeling tools for legacy products is that existing data from the longterm FSS can be used to verify the accelerated stability models. Once verified, the models can be applied to examine new formulations and processes. This is especially useful to select packaging configuration to support zone IVb countries. In some cases, a new study (properly designed to statistically probe a range of empirical models) may be needed to develop empirical models to accommodate the multitude of interactions.

\section{FDA PERSPECTIVE ON APPLICATION OF ICH Q8 TO LEGACY PRODUCTS, RAMESH RAGH AVACHARI, PH.D., CHIEF, BRANCH IX ONDQA/OPS/ CDER/FDA}

This talk defined the fundamental principles of ICH Q8, the meaning of a legacy product, and the advantages of these products in meeting the ICH Q8 guidelines. Three case studies were presented using three legacy products with postmarketing prior approval supplemental submissions. The agency's perspective was provided based on the expectations
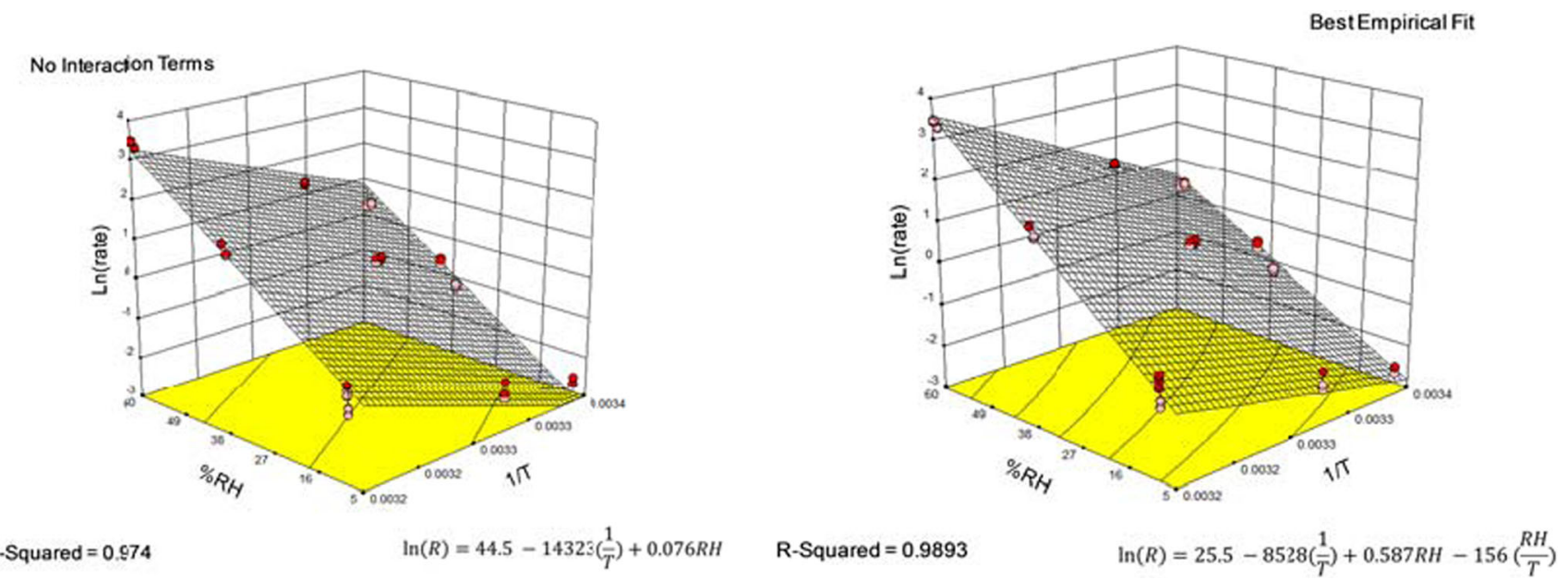

Fig. 1. An example where an empirical model gave a better fit than ASAP (no interactive terms) 


\section{Include All the Data into One Composite Model}

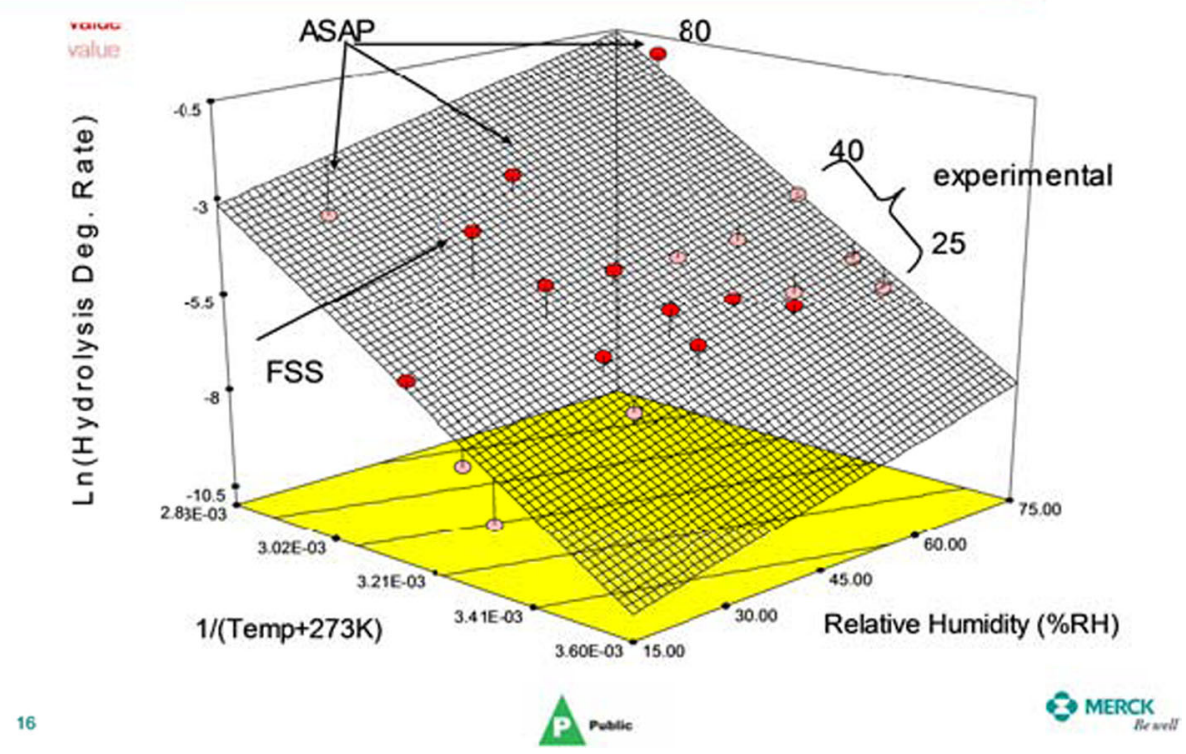

Fig. 2. Incorporation FSS data, ASAP, and experimental data

and deficiencies in each of these submissions. The scientific issues and resolution to these issues were discussed.

Dr. Raghavachari discussed the legacy product as a drug product having a proven record of safety and efficacy that has been in the market. To meet ICH Q8, the advantages of such legacy products are an established prior knowledge on

- Risks associated with each manufacturing step

- Impact of lot to lot variation

- Established critical quality attributes

- Known clinical relevance

- Knowledge of quality-related adverse events

- Expectations of an extended life cycle

The three case studies presented arrived at the agency at different times between 2005 and 2013. Each submission received significantly improved with time. Examples of quality by design (QbD)-based supplemental submissions of legacy products presented included

1. A drug substance manufacturing example involving a recrystallization and micronization process change for a solid oral dosage form product. A QbD-based design of experiment (DOE) was used to define a design space. This was an earlier submission and required discussion with the agency after a complete response. The amended application with a proposed real-time release test (RTRT) for micronization was accepted based on the design space model.

2. A non-sterile liquid dosage form example proposed to change to a real-time drug product release with a design space based on historical data with no analyses at release. This required some discussion with the agency, whereby some of the proposed changes were accepted after reinstating the testing at release and approved specifications through amendments.
3. Drug substance manufacturing for a solid oral dosage form was the third example. In this, a design space was provided for each and every step of the synthetic process to control the impurity profiles. This was a more recent submission which had a well-defined design space and control plan. The proposed QbD approach was readily accepted.

In each of these cases, a QbD approach was used along with a DOE study to define the product design space of the proposed changes. These post-approval applications, matured with more recent submissions providing solid data, can support real-time release, freedom to move within the design space, and specifications consistent with the proven model.

In conclusion, a procedure for legacy drug products should include

- Approach

- Leverage manufacturing experience as a part of ICH Q8 implementation

- Add laboratory/pilot experimentation as needed

- Outcome

- Supports continuous process improvement

- Can provide regulatory flexibility for future changes

\section{ASSESSMENT OF IMPACT ON STABILITY WITH MANUFACTURING, PACKAGING, AND/OR METHOD CHANGES, KIM HUYNH-BA, MANAGING DIRECTOR, PHARMALYTIK}

New medicines are developed daily and stability programs are necessary for product registration. Post-approval changes to the product require additional stability studies. There are several types of stability testing throughout the 
product life cycle: studies to support product development, studies to support registration or marketing application, studies to monitor product quality, and studies to support postapproval changes. As part of good manufacturing practices (GMP) requirements, pharmaceutical companies must establish a change control system to monitor any change to the product, process, or package as any such a change would risk the established stability profile of legacy products. Typical changes in the product life cycle are listed in Table I.

The QbD approach to the stability program of legacy products enables the use of the historical stability data to provide a better understanding of product stability and critical factors impacting the stability profiles. Historical data, however, may not accurately pinpoint the design space; therefore, additional stress testing may be done when changes are made to an approved product. Once a control space is understood, strategy can be developed and critical quality attributes (CQAs) can be identified.

The presentation discussed different types of risk mitigation with changes made to the current stability program. Depending on the change and based on product stability profile, risks must be evaluated to determine if new studies should be conducted or current studies can be continued. Changes can also be categorized as major or minor changes, while complex or multiple major changes should be avoided. It is important to link the data before and after changes when evaluating product stability through expiry.

A QbD approach can warrant a higher assurance of product availability and quality; however, it requires collaboration among different business units and across disciplines throughout the process. This would allow development teams to gain better understanding of the dynamic factors impacting the drug product. With this approach, one can avoid conducting additional stability studies and filings with changes from the initial registration. Avoiding repetitive testing for different regions can also reduce the cost and optimize available resources. Many companies, however, are not yet able to apply this concept due either to a lack of scientific knowledge, lack of resources, or complications of global submissions, which may have a major impact on timeline and product expiry. It was also noted that QbD concepts are not popular with global submission with many regional guidelines still not including QbD development. Although many global regulatory agencies are interested in the concept, the road for global acceptance of QbD is still challenged.

Table I. Typical Changes in Product Life Cycle

- Process changes (e.g., formulation, site, process, suppliers)

- Method changes (e.g., suppliers, new impurities, raw materials)

- New science and/or new technology

- New scientific or clinical findings

- Complying with regulatory or compendial changes

- Product improvement

- Changing of clinical/market needs

- Cost reduction

- Materials availability (new supplier/vendor)

- New sites/new facilities

- Market expansion

- Not meeting current product needs

\section{APPLYING ASEAN STABILITY REQUIREMENTS TO LEGACY PRODUCTS AND MANAGING SPEC IFICATIONS ACROSS CLIMATIC ZONES, KETAN SHAH, PH.D., DIRECTOR, GLOBAL QUALITY CONTROL, BIOGEN IDEC INC.}

Global stability guidelines have evolved since the first ICH Q1A guidance was issued in 1993. Based on the climatic conditions measured in certain parts of the world, a new zone IVB stability condition of $30^{\circ} \mathrm{C} / 75 \% \mathrm{RH}$ was adopted in 2005 by ASEAN countries and Brazil. Since issuance of the first ASEAN and ANVISA (Brazil) guidelines in 2005, many other countries in Latin America have adopted the zone IVB condition. Products developed prior to ASEAN/ANVISA guidelines can be considered legacy products and may not be necessarily designed to support shelf life under the new $30^{\circ} \mathrm{C} /$ $75 \% \mathrm{RH}$ long-term condition. The presentation outlined strategies to manage the impact of these emerging stability regulations on legacy products, and how to bring them up to the current regulatory standards in the impacted markets. The presentation also highlighted considerations in managing specifications across climatic zones for legacy products.

A summary of the current status of the ASEAN and ICH/ WHO stability requirements is presented in Fig. 3 below. Note the change to the humidity requirement for permeable containers in the ASEAN region aligned with $\mathrm{ICH} / \mathrm{WHO}$ guidelines.

When considering moving existing legacy products to the more stringent ASEAN climatic storage condition, the following simple decision tree was suggested (Fig. 4):

If new ASEAN stability studies are required, they should not be started without upfront data evaluation and risk assessment. Part of the decision-making process in starting a new ASEAN study for a legacy product requires a thorough evaluation of past stability data. Stability data from regulatory sections included in the filing that resulted in approvals in ASEAN markets should be reviewed along with any longterm data under non-ASEAN conditions, accelerated data as well as any special studies conducted to support excursions. A product-specific risk evaluation may be necessary, and if appropriate, products in similar product categories (e.g., same drug substance and similar dosage form) may be grouped for assessing stability risk. For certain legacy products, scientific literature should also be searched to understand instabilities associated with the compound and potential modes of degradation.

Based on the upfront evaluation and risk assessment, several potential corrective and preventive actions (CAPA) may be applied depending on the situation. For example, the shelf life of the product may be reduced to support a more stringent ASEAN stability condition or certain stabilityindicating impurity specifications may be widened with proper safety/toxicity justification. Alternatively, stability condition/ storage label may be changed to cold chain storage (e.g., refrigerated condition) for a temperature-sensitive product. Other options which require more effort and resources may include design of a more protective package, improving the manufacturing process/controls, or reformulation to a more stable product.

The presentation also highlighted considerations in managing specifications across climatic zones for legacy products. 


\section{Summary of ASEAN Guidance}

- ASEAN Guidelines: Issued Feb 2005, Implementation-Jan 2009, Revision - May 2013

\begin{tabular}{|c|c|c|}
\hline Type of Study & ASEAN & ICH/WHO \\
\hline General Case & $\begin{array}{l}30^{\circ} \mathrm{C} / 75 \% \text { RH - (LT) } \\
40^{\circ} \mathrm{C} / 75 \% \mathrm{RH}-(\mathrm{A})\end{array}$ & $\begin{array}{l}25^{\circ} \mathrm{C} / 60 \% \text { RH (Zone II - LT) } \\
30^{\circ} \mathrm{C} / 65 \% \text { RH (Zone IVA - LT) } \\
30^{\circ} \mathrm{C} / 75 \% \text { RH (Zone IV B - LT) } \\
40^{\circ} \mathrm{C} / 75 \% \text { RH - (A) }\end{array}$ \\
\hline $\begin{array}{l}\text { Aqueous products in } \\
\text { permeable containers }\end{array}$ & $\begin{array}{l}30^{\circ} \mathrm{C} / 75 \% \text { RH - (LT) } 2005 \\
30^{\circ} \mathrm{C} / 35 \% \text { RH - (LT) } 2013 \\
40^{\circ} \mathrm{C} / 75 \% \mathrm{RH}-(\mathrm{A})\end{array}$ & $\begin{array}{l}25^{\circ} \mathrm{C} / 40 \% \text { RH (Zone II - LT) } \\
30^{\circ} \mathrm{C} / 35 \% \text { RH (Zone IV - LT) } \\
40^{\circ} \mathrm{C} / \mathrm{NMT} 25 \% \text { RH - (A) }\end{array}$ \\
\hline $\begin{array}{l}\text { Products in impermeable } \\
\text { containers }\end{array}$ & $\begin{array}{l}30^{\circ} \mathrm{C} / \text { monitored } \mathrm{RH}-(\mathrm{LT}) \\
40^{\circ} \mathrm{C} / \text { monitored } \mathrm{RH}-(\mathrm{A})\end{array}$ & $\begin{array}{l}25^{\circ} \mathrm{C} / \text { monitor RH (Zone II - LT) } \\
30^{\circ} \mathrm{C} \text { /monitor RH (Zone IV - LT) } \\
40^{\circ} \mathrm{C} \text { /monitored RH - (A) }\end{array}$ \\
\hline $\begin{array}{l}\text { Refrigerated/Freezer } \\
\text { products }\end{array}$ & \multicolumn{2}{|c|}{ Harmonized requirements across climatic zones } \\
\hline
\end{tabular}

Fig. 3. Current status of the ASEAN and ICH/WHO stability requirements

Considerations around test attributes and test methods, release and stability specifications as well as expiry/retest period and label storage conditions were discussed. Whenever possible, same test methods and attributes should be filed in all markets globally. If different specifications are filed in various markets, the company should device internal strategies to test materials to the tightest "global" specifications or segregate material based on regional or country-specific tests and specifications. Considerations should also be given to effectively implement new and improved methods as part of product life cycle management. Although many companies desire to have one global specification, this may not be possible in most instances. Therefore, companies should design their internal systems (e.g., LIMS and/or ERP systems) to manage different specification versions to serve global markets. These systems should also be able to accommodate different shelf life and label storage statements aligned with market approvals for the legacy products.

\section{CONCLUSION AND FUTURE DIRECTION}

Changes are inevitable; therefore, in bringing marketing authorizations of legacy drug products to current regulatory standards, a QbD approach may be advantageous to support these changes in a post-approval submission. Such approaches have been accepted by various regulatory agencies, including the FDA. The advantage of working with legacy products is that significant historical data and information are available to build stability models to sup-

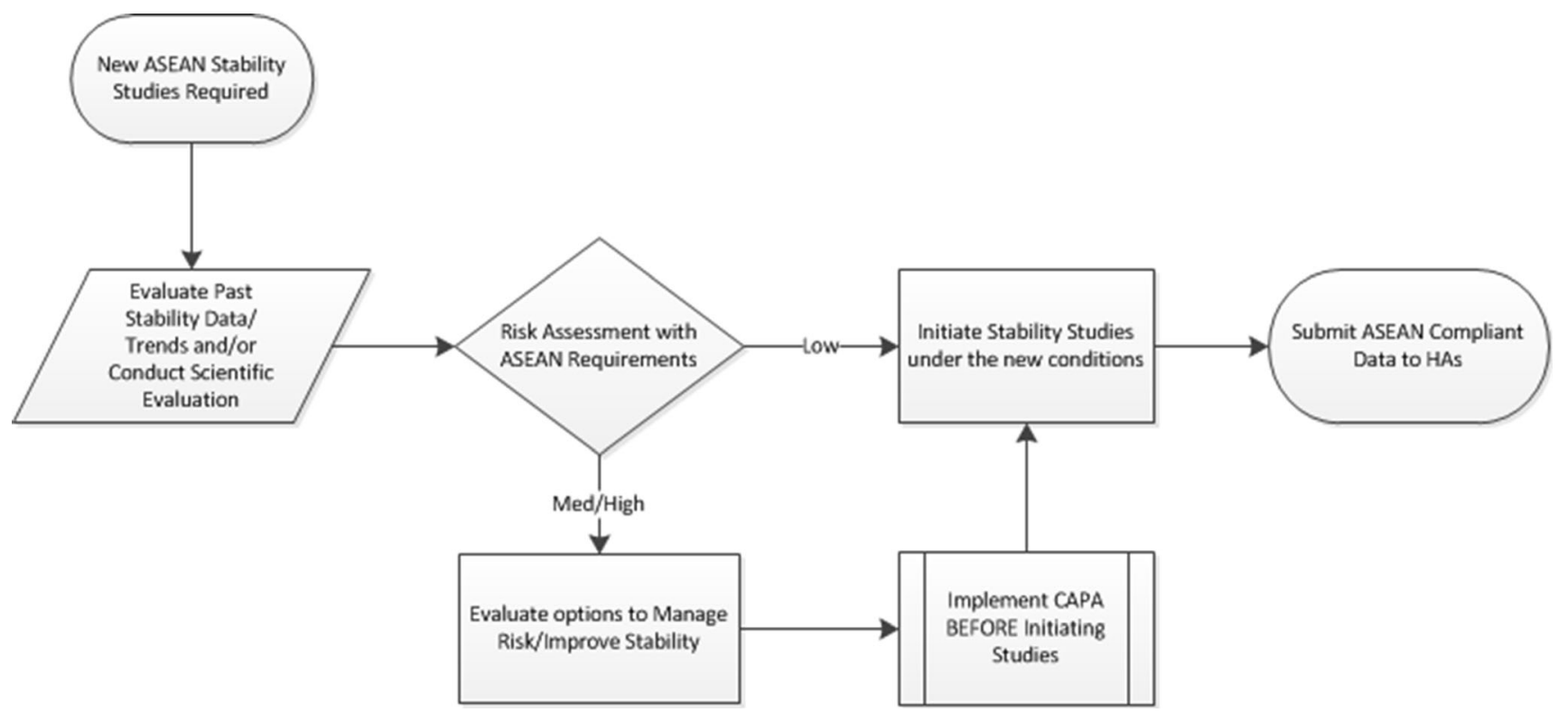

Fig. 4. Decision tree to bring legacy products to current ASEAN standards 
port changes. However, additional stress testing and experimental stability studies may be necessary to allow the development teams to gain a better understanding of the stability profiles of their products. Risks and benefits must also be evaluated based on the level of change. In addition, it is a challenge to manage changes in submissions across multiple regions with legacy products, as requirements and specifications may be different from country to country.

Since 2004, ASEAN has issued a new stability guidance that requires more stringent storage conditions for products marketed in their region. To support ASEAN stability studies, all available historical data should be evaluated and the risk of meeting shelf life specifications should be assessed prior to starting a stability program under the new storage conditions. Appropriate corrective and preventive actions should be implemented if the risk of non-conformance is medium to high as suggested in the article. Additional packaging may be considered to provide additional protection to the products. Companies may also need to devise unique strategies and systems to manage different specifications across various markets/regions to comply with the emerging regulatory requirements globally.

Disclaimer This article represents the opinion of the authors and not necessarily those of their respective companies/organizations.

\section{REFERENCES}

1. ICH Q8, 9 and 10 Guidelines http://www.fda.gov/downloads/ aboutfda/centersoffices/officeofmedicalproductsandtobacco/cder/ manualofpoliciesprocedures/ucm242665.pdf

2. Guidance for industry, "Q8(R2) Pharmaceutical Development" (Nov 2009) http://www.fda.gov/downloads/Drugs/ GuidanceComplianceRegulatoryInformation/Guidances/ ucm073507.pdf

3. Guidance for industry, "Q9 Quality Risk Management" (June 2006) http://www.fda.gov/downloads/Drugs/ GuidanceComplianceRegulatoryInformation/Guidances/ ucm073511.pdf

4. Guidance for industry, "Pharmaceutical Quality Systems" (April 2009 ) http://www.fda.gov/downloads/Drugs/ GuidanceComplianceRegulatoryInformation/Guidances/ ucm073517.pdf

5. Guidance for industry, "Q8, Q9, and Q10 Questions and Answers" (May 2010) http://www.fda.gov/downloads/Drugs/ GuidanceComplianceRegulatoryInformation/Guidances/ UCM210822.pdf

6. Guidance for industry - changes to an approved NDA or ANDA http://inside.fda.gov:9003/downloads/programsinitiatives/drugs/ projectmanagement/ucm372912.pdf

7. Guidance for industry-SUPAC-MR: modified release solid-oral dosage forms http://www.fda.gov/downloads/drugs/ guidancecomplianceregulatoryinformation/guidances/ ucm070640.pdf

8. Post-approval change management: challenges and opportunities-an FDA perspective http://www.fda.gov/downloads/aboutfda/ centersoffices/officeofmedicalproductsandtobacco/cder/ucm406881.pdf

9. Waterman $\mathrm{KC}$, Colgan ST. A science-based approach to setting expiry dating for solid drug products. Regul Rapporteur. 2008;5:7/8.

10. Waterman KC, MacDonald BC. Package selection for moisture protection for solid, oral drug products. J Pharm Sci. 2010;99(11):4437-52. 